\title{
Predicting the metabolic cost of walking while wearing explosive ordnance disposal protective clothing
}

\author{
Aaron Bach ${ }^{1 *}$, David Borg ${ }^{1}$, Joseph Costello ${ }^{1,2}$, lan Stewart ${ }^{1}$ \\ From 15th International Conference on Environmental Ergonomics (ICEE XV) \\ Portsmouth, UK. 28 June - 3 July 2015
}

\section{Introduction}

The use of improvised explosive devices (IED) is becoming more prevalent in modern warfare, civil unrest and lone wolf terrorism. This has led to a greater role for explosive ordnance disposal (EOD) technicians to neutralise the threat of IED detonations. As such, the inherent risk to EOD technicians requires them to don a heavy $(\sim 34 \mathrm{~kg})$ protective ensemble that subsequently increases the metabolic demand of tasks, such as locomotion. Previous research into the metabolic cost of protective clothing has focused primarily on chemical and fire ensembles [1]. Currently little is known about the metabolic cost of EOD protective clothing. The purpose of this investigation was 1) to quantify the metabolic demand when wearing an EOD ensemble at various speeds of locomotion and 2) establish whether the Pandolf predictive formula [2] is appropriate to estimate of EOD energy expenditure.

\section{Methods}

Seven males (mean(SD) 26 (4) years, $1.82(0.05) \mathrm{m}$, $83.7(10.0) \mathrm{kg}, 4.3\left(0.4 \mathrm{~L} \mathrm{~min}^{-1}\right)$ completed six treadmill walking trials at $2.5,4$ and $5.5 \mathrm{~km} \cdot \mathrm{h}^{-1}$ (1\% grade) while wearing normal athletic clothing (CON) or an EOD-9 military ensemble (EOD) in a randomised order. Steady state oxygen consumption $\left(6^{\text {th }}\right.$ to $8^{\text {th }}$ minute $)$ was measured to determine the metabolic cost. Observed energy expenditure was also compared to those predicted using Pandolf's formula [2].

\footnotetext{
* Correspondence: aj.bach@qut.edu.au

${ }^{1}$ Institute of Health and Biomedical Innovation, Queensland University of

Technology, Brisbane, Australia

Full list of author information is available at the end of the article
}

\section{Discussion}

This study suggests that a strong correlation $\left(r^{2}=0.97\right)$ is present between observed and predicted EOD energy expenditure. Although, due to the constant under-estimation of the predictive formula based on traditional load carriage (i.e. backpack) it may be necessary to make adjustments to the predictive formula to account for the variation in load carriage while wearing the EOD ensemble. For example, the distribution of load around the body, potentially changes gait mechanics due to ensemble size/thickness and increased friction of locomotion.

\section{Conclusion}

The largest differences in energy expenditure were seen at the fastest speed and although strong correlations are present between observed and predicted EOD energy expenditure, the formula significantly underestimated the metabolic cost of walking in an EOD ensemble at every speed tested.

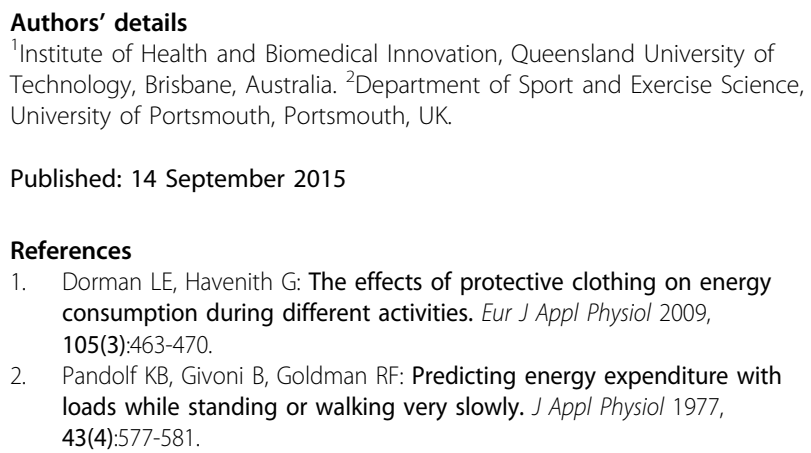

Published: 14 September 2015

References

1. Dorman LE, Havenith $\mathrm{G}$ : The effects of protective clothing on energy consumption during different activities. Eur J Appl Physiol 2009, 105(3):463-470.

2. Pandolf KB, Givoni B, Goldman RF: Predicting energy expenditure with loads while standing or walking very slowly. J Appl Physiol 1977, 43(4):577-581. 


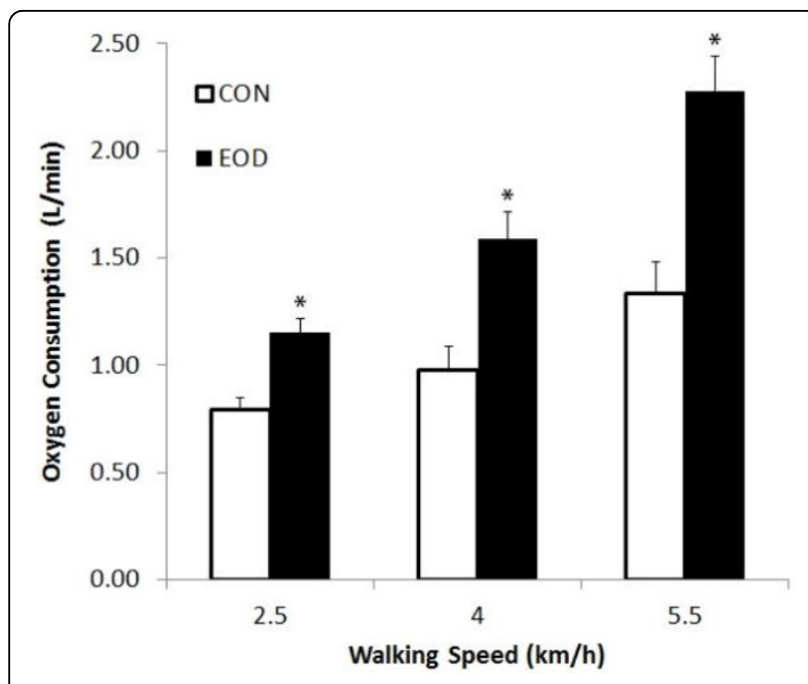

Figure 1 Oxygen consumption between CON and EOD at different walking speeds. ${ }^{*}$ significantly different to CON at same speed $(p<0.05)$.

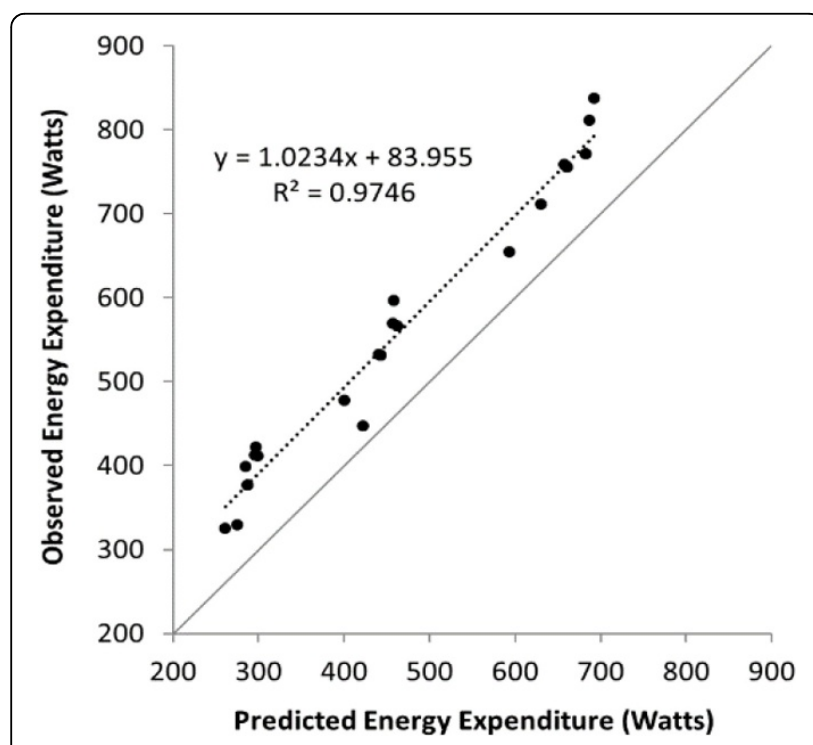

Figure 2 EOD energy expenditure (W) observed vs. predicted from Pandolf [1].

doi:10.1186/2046-7648-4-S1-A78

Cite this article as: Bach et al.: Predicting the metabolic cost of walking while wearing explosive ordnance disposal protective clothing. Extreme Physiology \& Medicine 2015 4(Suppl 1):A78.
Submit your next manuscript to BioMed Central and take full advantage of:

- Convenient online submission

- Thorough peer review

- No space constraints or color figure charges

- Immediate publication on acceptance

- Inclusion in PubMed, CAS, Scopus and Google Scholar

- Research which is freely available for redistribution

Submit your manuscript at www.biomedcentral.com/submit
C Biomed Central 